University of Nebraska - Lincoln

DigitalCommons@University of Nebraska - Lincoln

Papers in Ornithology

Papers in the Biological Sciences

2011

\title{
Use of Nape Tags for Marking Offspring of Precocial Waterbirds
}

Todd W. Arnold

University of Minnesota - Twin Cities, arnol065@umn.edu

Daizaburo Shizuka

University of Nebraska-Lincoln, dshizuka2@unl.edu

Bruce E. Lyon

University of California, Santa Cruz, belyon@ucsc.edu

Jeffrey T. Pelayo

University of Saskatchewan

Katherine R. Mehl

University of Saskatchewan

See next page for additional authors

Follow this and additional works at: https://digitalcommons.unl.edu/biosciornithology

Part of the Poultry or Avian Science Commons, and the Zoology Commons

Arnold, Todd W.; Shizuka, Daizaburo; Lyon, Bruce E.; Pelayo, Jeffrey T.; Mehl, Katherine R.; Traylor, Joshua J.; Reed, Wendy L.; and Amundson, Courtney L., "Use of Nape Tags for Marking Offspring of Precocial Waterbirds" (2011). Papers in Ornithology. 84.

https://digitalcommons.unl.edu/biosciornithology/84

This Article is brought to you for free and open access by the Papers in the Biological Sciences at DigitalCommons@University of Nebraska - Lincoln. It has been accepted for inclusion in Papers in Ornithology by an authorized administrator of DigitalCommons@University of Nebraska - Lincoln. 


\section{Authors}

Todd W. Arnold, Daizaburo Shizuka, Bruce E. Lyon, Jeffrey T. Pelayo, Katherine R. Mehl, Joshua J. Traylor, Wendy L. Reed, and Courtney L. Amundson 


\title{
Use of Nape Tags for Marking Offspring of Precocial Waterbirds
}

\author{
Todd W. Arnold ${ }^{1, *}$, Daizaburo ShizUkA ${ }^{2}$, Bruce E. LyON ${ }^{2}$, JeFFrey T. PELAYO ${ }^{3,4}$, \\ KATHerine R. MeHL ${ }^{3,5}$, Joshua J. Traylor ${ }^{3}$, Wendy L. ReED ${ }^{6}$ And Courtney L. Amundson ${ }^{1}$ \\ ${ }^{1}$ Department of Fisheries, Wildlife, and Conservation Biology, University of Minnesota, 1980 Folwell Avenue, \\ St. Paul, MN, 55108, USA
}

${ }^{2}$ Department of Ecology and Evolutionary Biology, University of California, Santa Cruz, CA, 95064, USA

${ }^{3}$ Department of Biology, University of Saskatchewan, 112 Science Place, Saskatoon, SK, S7N 5E2, Canada

${ }^{4}$ Current address: 9056 Blackdog Alley \#1, Easton, MD, 21601, USA

${ }^{5}$ Current address: Department of Environment and Conservation - Wildlife Division, Confederation Building, St. John's, NL, A1B 4J6, Canada

${ }^{6}$ Department of Biological Sciences, North Dakota State University, 311 Stevens Hall, Fargo, ND, 58105, USA

*Corresponding author; E-mail: arnol065@umn.edu

\begin{abstract}
Individualized markers that allow organisms to be identified without recapture are invaluable for studies of survival, movement, and behavior. Nape tags consisting of brass safety pins with unique combinations of two or three colored plastic beads were used to mark 5,868 American Coot (Fulica americana) chicks and 331 Ruddy Duck (Oxyura jamaicensis), 157 King Eider (Somateria spectabilis) and 664 White-winged Scoter (Melanitta fusca deglandi) ducklings. These markers allowed for documentation of parent-offspring interactions, post-hatching survival, brood movements and brood-mixing behaviors. Nape tags were inexpensive, easy to make, easy to observe with binoculars or spotting scopes and provided over 100 two-bead or 1,000 three-bead color combinations for individual identification. For coots, there was no evidence of color biases affecting parental care or offspring survival, although some colors (white, yellow) were easier to detect than others (brown). The only observed problem was marker loss, with tag loss rates reaching $20 \%$ near fledging age. Nape tags worked effectively on coots and ducklings and may be useful for other precocial waterbirds. Received 4 February 2011, accepted 3 May 2011.
\end{abstract}

Key words.-American Coot, color marking, King Eider, nape tag, resighting, retention, Ruddy Duck, survival, White-winged Scoter.

Waterbirds 34(3): 312-318, 2011

Monitoring post-hatching survival of precocial birds can be difficult due to mobility and secretive behavior of offspring, combined with a lack of suitable marking methods to allow for individual identification. Although hatchling shorebirds can often be marked using adult-sized leg bands (Sharpe et al. 2009), this option is not suitable for young waterfowl (Anseriformes) or rails (Rallidae). Previous methods of marking precocial waterbirds have included colordyeing plumage either before or after hatch (Evans 1951; Eadie and Lyon 1998), web tagging (Alliston 1975), web clipping (Eichhorst 1986), plasticine-filled leg bands (Blums et al. 1994), colored nasal-tags (Sugden and Poston 1968), and miniature radio transmitters (Mauser and Jarvis 1991). Color dyeing has limited utility because of fading colors, minimal color combinations, and risk of embryo mortality if done in the egg (Evans 1951). However, in species with white color patches (e.g. Bucephala ducklings), color dyes can be effective for brood-level recognition (Eadie and Lyon 1998). Although web tags, web clipping, and plasticine-filled leg bands can provide useful data if offspring are subsequently recaptured or recovered (Blums et al. 1994), they do not allow individuals to be identified from a distance, limiting their usefulness for mark-resighting studies. Nasal markers are widely used for many species of waterfowl, but ducklings cannot be marked reliably until they are approximately 30 days old (Anderson et al. 2001). Radio transmitters with subcutaneous anchors have been used on day-old Mallard (Anas platyrhynchos) ducklings with no apparent effects (Mauser and Jarvis 1991); however, other investigators have found detrimental ef- 
fects on duckling survival (Amundson and Arnold 2010b) and such markers are often prohibitively expensive.

Although nape tags were developed more than 50 years ago (Gullion 1951; Foley 1956), they have been used infrequently. Gullion (1951) found that nape tags had a retention span of up to three months on American Coots (Fulica americana), but the nickel-plated brass safety pins he used for attachment caused an acute tissue reaction. Foley (1956) found that $70 \%$ of Mallard ducklings retained nape tags from hatch until fledging. Kehoe and Mawhinney (1999) evaluated several markers on domestic Mallard ducklings, including nape tags; however, only nasal discs were recommended as a suitable marking method based on $100 \%$ retention to eight weeks of age. However, in all these examples nape tags consisted of large $(2 \times 3 \mathrm{~cm}, 2.5 \times 10 \mathrm{~cm})$ plastic or vinyl flags attached to stainless steel safety pins.

Lyon (1993) developed small nape tags consisting of size 00 brass safety pins with colored seed beads threaded onto the back of the pin; however, these tags were difficult to identify at distances beyond $20 \mathrm{~m}$. In this paper, we describe our experiences using two modified nape tag designs that utilized a brass safety pin with larger colored markers consisting of either Perler beads or modified shorebird color bands (Fig. 1). These markers allowed us to identify offspring at distances up to $150 \mathrm{~m}$ and document behavioral interactions, movements and survival.

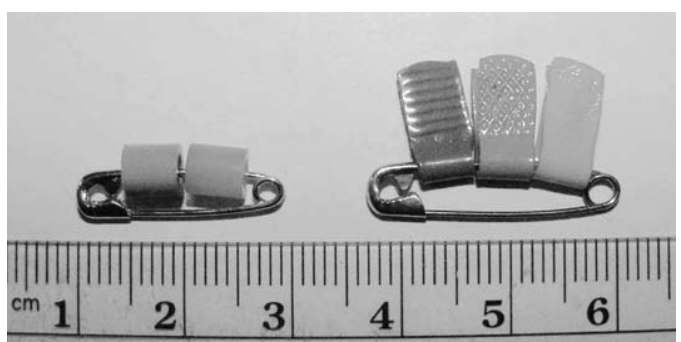

Figure 1. Nape tag designs used on American Coot and Ruddy Duck hatchlings (left; pin size 00 with two plastic Perler beads) and on King Eider and White-winged Scoter ducklings (right; pin size 0 with three plastic colorband tabs).

\section{METHODS}

Study Areas and Species

We studied American Coots during 1991 (Arnold 2011), 1997-1999 (Reed et al. 2009), and 2004-2005 (Amundson and Arnold 2010a) and Ruddy Ducks (Oxyura jamaicensis) during 1998-1999 (Pelayo and Clark 2003) in the prairie pothole region of Minnedosa, Manitoba, Canada. Shizuka and Lyon (2010) studied coots during 2005-2008 at several large wetlands near Williams Lake, British Columbia, Canada. King Eiders (Somateria spectabilis) were studied during 2000-2001 at Karrak and Adventure Lakes, approximately $60 \mathrm{~km}$ south of the Queen Maud Gulf Bird Sanctuary, Nunavut, Canada (Mehl and Alisauskas 2007) and White-winged Scoters (Melanitta fusca deglandi) were studied during 2000-2001 at Redberry Lake, Saskatchewan, Canada (Traylor and Alisauskas 2006).

\section{Capture and Marking}

We visited coot nests daily throughout the hatching period and collected pipping eggs and placed them into individualized compartments in an artificial incubator (Reed et al. 2009). After hatch, chicks were kept in the incubator until dry (usually 3-4 h) and fitted with a nape tag consisting of a brass safety pin (size 00 ) with two plastic Perler beads (Perler Beads, Reading, PA 19604-1527, USA; http://perler.eksuccessbrands.com). We created tags by unwinding the spiral spring on the safety pin, threading two beads onto the back wire, and then rewinding the spring (Fig. 1). Safety pins were inserted through an approximately $1.0 \mathrm{~cm}$ pinch of loose skin just below the base of the skull. Beginning in 1997, we placed a small dab of Triple antibiotic ointment on pins prior to insertion. Pins were always inserted so that the clasp was on the left side of the chick's body and combinations were read from left to right (Fig. 2A). Chicks were released back into nest bowls, usually within twelve hours of hatching, and were readily accepted by attendant adults. All of our studies involved experimental transfers of coot young among nests, but care must be taken when creating manipulated broods not to release foreign chicks after parents have already imprinted on their own offspring, or infanticide can occur (Shizuka and Lyon 2010). In Manitoba, chicks were observed for 15-60 minute bouts at 3-7 day intervals until 35-60 days of age using $15-60 \times$ spotting scopes mounted on vehicles or tripods (Reed et al. 2009; Amundson and Arnold 2010a; Arnold unpubl. data), whereas in British Columbia chicks were observed from floating blinds every 3-5 days during the first 20-30 days post-hatching (Shizuka and Lyon 2010).

We collected entire clutches from Ruddy Ducks and King Eiders during late incubation, replaced them with an identical number of non-fertile chicken eggs, and hatched them in artificial incubators. White-winged Scoter ducklings hatched naturally and were marked in their nest bowls within 24 hours of hatching. Ruddy ducklings were fitted with the same tags as used on coots, and one duckling in each brood was left as an unmarked control (Pelayo 2001). Eider and scoter ducklings were marked with a plasticinefilled metal leg band (Blums et al. 1994) and a nape tag that consisted of a brass safety pin (size 0 ) with three colored plastic tabs (Fig. 1; right marker). 


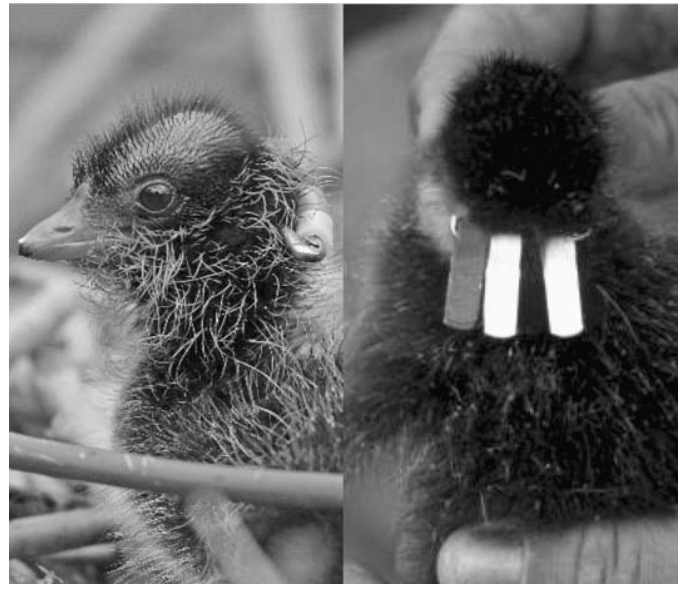

Figure 2. Examples of proper tag placement on an American Coot chick (left panel) and White-winged Scoter duckling (right panel). The nape tags are placed through approximately 1 to $1.5 \mathrm{~cm}$ of skin immediately below the base of the skull, where they cannot be reached during preening. Coot chicks with tags placed through too little skin or lower on the neck were more likely to get their lower bill caught in the tag and or lose their tags. The large tabs on duckling tags facilitated observation from $>100 \mathrm{~m}$.

Shorebird leg-band blanks (A. C. Hughes, Middlesex TW12 1NA, England) were bent in half over a nail, held tightly in place with pliers, and submerged briefly into boiling water. Tabs were air dried before gluing into place over the fixed portion of the safety pin with clear polyvinyl chloride cement. Before attaching nape tags, insertion sites were cleaned using $95 \%$ ethanol and tags were inserted similarly to coots (Fig. 2), using a small dab of Polysporin antibiotic. Ruddy and eider ducklings were returned to their nests in a loosely-stapled paper towel envelope to prevent them from escaping (Korschgen et al. 1996). Nesting females were nasal-marked (all species) and radiomarked (eiders only) to facilitate locating broods and we monitored duckling survival for 24-31 days post-hatch using 15-56x binoculars or spotting scopes (Pelayo and Clark 2003; Traylor and Alisauskas 2006; Mehl and Alisauskas 2007).

\section{Statistical Analyses}

In 1991, we recorded the number of untagged coot chicks during each daily survey occasion. Since chicks that had lost their markers could not be reliably aged, unmarked chicks were assigned the mean age of their marked broodmates. Polynomial regression was used to determine how the proportion of marked chicks changed with age. Detection and survival probabilities of marked chicks were assessed in relation to bead color (blue, brown, green, orange, pink, red, violet, white, and yellow) using a Cormack-Jolly-Seber analysis in Program MARK (White and Burnham 1999). A similar model was used to measure differences in marker retention between chicks marked by two different observers. Other covariates affecting detection and survival probabilities included chick age, brood size, hatching order, hatching date, and supplemental feeding, and these ef- fects were included to control for potential confounding effects, but are not reported herein (Arnold, unpubl. data).

In 2005-2008, we assessed tag loss by observing marked coot chicks every 3-5 days from floating blinds $(\bar{x}=6.3$ surveys per brood) for $20-35$ days after hatching. Brood surveys and behavioral observations were conducted at close range $(10-40 \mathrm{~m})$ from floating blinds equipped with camouflage coverings, where nape tags could be easily observed using $7 \times 35$ binoculars (see Shizuka and Lyon 2010 online supplemental materials). Tag loss was assumed when an untagged chick was observed concurrent with the disappearance of a marked chick.

We tested for effects of tag color on parental investment and chick survival by comparing feeding rates, parental aggression and survival rates of coot chicks with red or orange tags vs. other colors (Lyon et al. 1994). Comparisons of feeding and parental aggression (i.e. tousling behavior; Shizuka and Lyon 2010) were based on several one-hour focal observation periods, supplemented with opportunistic non-focal observations. Focal observations involved observing one parent for 30 minutes, then the other parent for the remaining 30 minutes. To assess the effects of nape tag color on parental feeding rate, tousling rate and chick survival, we constructed generalized linear mixed models with tag color as a fixed effect, hatch order as a fixed effect (survival only) and brood as a random effect, and used loglikelihood ratios to test for the effects of tag color by comparing the full model against a model without the color effect.

We assessed potential effects of nape tags on survival of Ruddy Ducks by comparing survival of unmarked control ducklings (one per brood) with nape-tagged broodmates using known-fates survival models in Program MARK (White and Burnham 1999). Additional covariates included year, hatch date, duckling size, duckling condition, female size and a variable denoting inclement weather (Pelayo 2001; Pelayo and Clark 2003). We assessed potential effects of nape tags on duckling survival by calculating likelihood ratio tests on otherwise identical pairs of models that differed only in presence of a marker effect.

\section{RESULTS}

We marked 5,868 American Coot chicks with nape tags in $1991(\mathrm{~N}=1,060), 1997$ $1999(\mathrm{~N}=1,611), 2004-2005(\mathrm{~N}=662)$, and 2005-2008 ( $\mathrm{N}=2,535)$. In 1991 , the proportion of unmarked chicks increased with mean age $(\mathrm{Y}=0.048-0.0006 \times$ Age +0.00006 $\times$ Age $\left.^{2} ; R^{2}=0.59, P<0.0001\right)$; mean estimated tag loss was $<10 \%$ for the first 40 days but exceeded $20 \%$ after 60 days (Fig. 3). Apparent survival to 40 days of age was 0.502 ( $\mathrm{SE}=$ 0.048 ) for 860 coot chicks marked by the senior investigator versus $0.314(\mathrm{SE}=0.042)$ for 197 chicks marked by an assistant, a difference that we attribute to tag loss rather than mortality. At least 27 coots marked in 


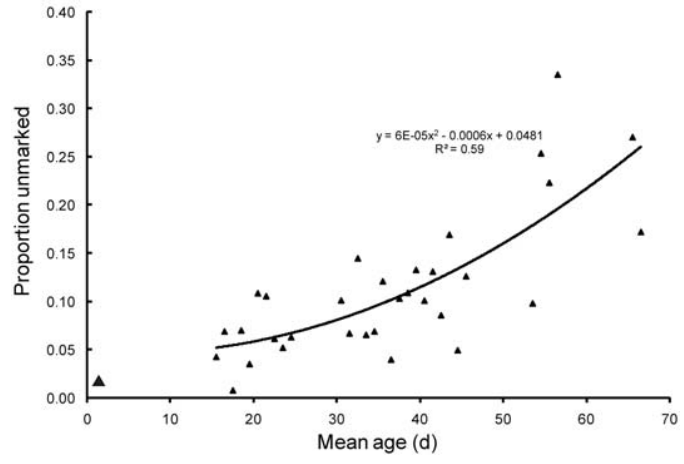

Figure 3. Loss of nape tags through time from American Coot chicks in 1991. Since unmarked chicks were of unknown age, they were assigned the mean age of their marked broodmates. The expected value of unmarked chicks given no marker loss was 0.022 (large triangle at age 1), the proportion of chicks in marked broods that hatched before they could be marked. Observations did not begin until ten days after hatching.

1991 still had tags after 70 days, but regular observations ceased when chicks reached 60 days of age. Observed tag loss during the first 30 days of life averaged $5.9 \%$ over four years in British Columbia, but was lower in the last two years when all chicks were marked by a single investigator (Table 1). Cumulative tag loss was small relative to total mortality, especially during the last two years (Fig. 4). Losing a tag did not affect subsequent survival $\left(\chi^{2}=1.3, P=0.26, \mathrm{~N}=16\right.$ broods $)$. Although parents frequently tousled chicks (Shizuka and Lyon 2010), we never observed tag loss resulting from tousling. Six chicks from the British Columbia study still retained nape tags in subsequent years when they were observed as breeding adults.

The presence of red or orange tags had no effect on feeding rate $\left(\chi^{2}=2.2, P=0.14\right)$

Table 1. Observed losses of nape tags from American Coot chicks during the first $\mathbf{3 0}$ days of life in British Columbia, 2005-2008. Numbers are total tagged chicks released at nests, total chicks observed at a later age, chicks observed with apparent tag loss, and percent tag loss.

\begin{tabular}{lrrrc}
\hline \hline Year & Tagged & Observed & Tag loss & $\%$ tag loss \\
\hline 2005 & 342 & 303 & 23 & 7.6 \\
2006 & 928 & 683 & 63 & 9.2 \\
2007 & 647 & 499 & 24 & 4.8 \\
2008 & 618 & 527 & 9 & 1.7 \\
Totals & 2,535 & 2,012 & 119 & 5.9 \\
\hline
\end{tabular}
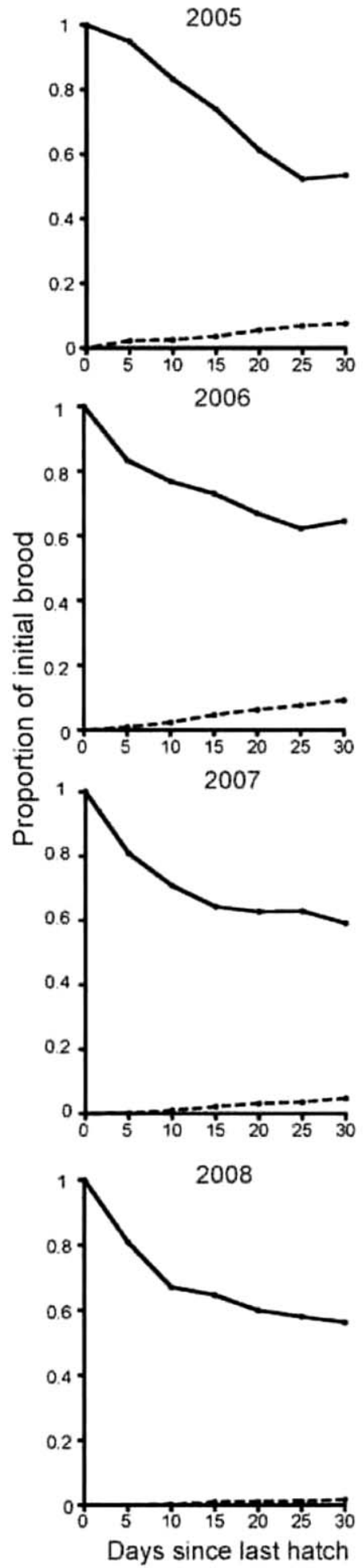

Figure 4. Cumulative survival of American Coot chicks (top solid line) vs. cumulative loss of nape tags (bottom dashed line) during the first $30 \mathrm{~d}$ post-hatching in British Columbia, 2005-2008. 
or tousling rate of coot chicks in British Columbia $\left(\chi^{2}=0.01, P=0.94, \mathrm{~N}=63\right.$ broods). Survival declined significantly with increasing hatching order $\left(\chi^{2}=16.0, P<0.0001\right)$, but was not affected by the presence of red or orange tags $\left(\chi^{2}=1.0, P=0.33\right)$. In 1991 , survival of coot chicks was not influenced by any of the ten tag colors that were used $(\mathrm{Z} \leq$ $1.22, P \geq 022$ for all colors), and our analysis had $85 \%$ power to detect survival differences of 0.042-0.049 at early ages (0-20 days of age) and 0.014-0.020 at later ages (20-40 days of age). However, detection probabilities were higher for chicks marked with white or yellow and lower for chicks marked with brown beads (Fig. 5), and a model recognizing these differences in detection probabilities had an 11.48 reduction in $\mathrm{AIC}_{\mathrm{c}}$ versus an otherwise identical model that treated all colors equally.

On three occasions in 1991 and two occasions in 2004-2005, coot chicks were observed with their lower bill caught in the safety pin, but all five chicks were observed later and had freed their bills. No deleterious effects of markers were observed for 56 nape-marked coots kept in captivity for three years.

We marked 331 Ruddy Ducks, 157 King Eiders, and 664 White-winged Scoters using uniquely colored nape tags. Other than scar tissue following tag loss, no effects of nape tags were observed on ducklings. In four different contrasts, nape tags had no significant effect on survival of Ruddy Ducks $\left(\chi^{2}=1.29\right.$ 2.12, $P=0.15-0.26)$; moreover, this was the

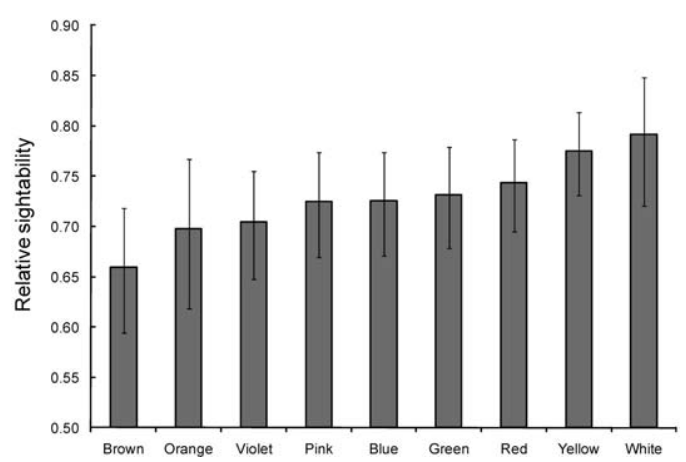

Figure 5. Relative effect of tag colors on detection probabilities ( $\pm 85 \%$ confidence intervals) of 40 -d old American Coot chicks at Minnedosa, Manitoba in 1991. only covariate examined that had no effect on survival, indicating that study design and sample sizes were adequate to detect meaningful real differences in survival (Pelayo 2001). Survival of both King Eider and White-winged Scoter ducklings was extremely low $(\leq 0.10)$ due to predation by gulls (Larus spp.), but there was no evidence that gulls specifically targeted marked ducklings (Traylor and Alisauskas 2006; Mehl and Alisauskas 2007). The percentage of marked White-winged Scoter ducklings did not change from $<2$ d of age ( $46 \%$ of 385 ducklings observed) to $\sim 28 \mathrm{~d}$ after hatch $(39 \%$ of 72 ducklings observed), suggesting minimal effect of markers on survival and little potential for tag loss $\left(\chi^{2}=1.3, P=0.25\right)$. However, two 28-d-old scoter ducklings were sighted with plasticine-filled leg bands only, indicating some nape-tag loss. White-winged Scoter ducklings retained their markers for up to 60 d, and four Ruddy Duck ducklings retained their markers for at least $43 \mathrm{~d}$.

\section{DISCUSSION}

Nape tags provided us an effective and affordable means of marking large numbers of coots and ducklings under a variety of field conditions, and based on our experiences we suspect they would also be effective for marking hatchling loons, grebes, goslings and gallinaceous birds. Nape tags were retained long enough to meet our single-season study objectives, although some loss of information occurred in coot broods when two or more chicks per brood lost markers. In two of our studies we observed lower rates of tag loss when tags were applied by a single experienced observer, indicating the importance of training and experience. To obtain unbiased estimates of survival using nape tags, we recommend that investigators concurrently assess rates of marker loss.

We observed no concerns related to animal welfare. Chicks typically exhibited little or no reaction to being marked, and marking appeared to cause less discomfort than other commonly-used marking methods that we have used including web-clipping (Eichhorst 1986) and web-tagging (Alliston 1975). 
A few coot chicks got their bills caught in their markers, but managed to free themselves later; they may have been marked too low on the neck. We were concerned about potential impacts of marker colors with coot chicks given their colorful ornamentation and previous demonstration of parental preferences for such ornamentation (Lyon et al. 1994); however, we found no difference in rates of feeding, tousling, or survival among coot chicks marked with different color combinations.

Bead colors that offered the best visibility under varying light conditions included yellow and white, whereas brown beads had lower visibility. Visibility was only assessed on coot chicks, but ducklings had dark natal plumages and we expect similar results. Our studies needed enough color combinations to uniquely identify up to 130 different chicks per wetland, which required a minimum of eleven different colors using one or two bead combinations. For some of our studies, rapid identification of individual chicks was important (Lyon et al. 1994; Shizuka and Lyon 2010) and, in such cases, the vibrant florescent colors of some Perler beads (orange, pink and green) were especially helpful. Future investigators might consider using corrosion-resistant stainless steel pins, which were not readily available when we began our studies. We also suspect that there is little benefit from using ethanol or topical antibiotics on insertion sites, and recommend that future investigators discuss this issue with their animal care committees.

\section{ACKNOWLEDGMENTS}

Delta Waterfowl Foundation provided financial or logistical support to six of our studies. We also thank the Arctic Institute of North America, Canadian Wildlife Service (Prairie and Northern Wildlife Research Centre), Institute for Wetlands and Waterfowl Research (Ducks Unlimited Canada), the National Science Foundation, Nunavut Wildlife Management Board, Polar Continental Shelf Project, Redberry Lake World Biosphere Reserve, University of Alberta, University of California, University of Minnesota, University of Saskatchewan and Iowa State University for additional funding and logistical assistance. Capture and marking procedures were approved by animal care committees at the University of Saskatchewan (Protocols 980022, 20000010), the University of California Santa Cruz (2008044), the University of Minnesota (0503A68157,
0505A70092), Iowa State University (11-7-3716-1QG) or the Manitoba Wildlife Institutional Animal Care and Use Committee (MWACC 1997-02, 1998-02, 2004-01) and federal access and scientific permits were issued on behalf of the Canadian Wildlife Service (WS-M47, WSM74, CWS 10569, CWS98-M015, CWS99-M020, MB091958-0, 03622-Z). Numerous research assistants and colleagues helped make our studies possible.

\section{Literature Cited}

Alliston, G. W. 1975. Web tagging ducklings in pipped eggs. Journal of Wildlife Management 39: 625-628.

Amundson, C. L. and T. W. Arnold. 2010a. Anthelmintics increase survival of American Coot (Fulica americana) chicks. Auk 127: 653-659.

Amundson, C. L. and T. W. Arnold. 2010b. Effects of radiotransmitters and plasticine bands on Mallard duckling survival. Journal of Field Ornithology 81: 310-317.

Anderson, M. G., M. S. Lindberg and R. B. Emery. 2001. Probability of survival and breeding for juvenile female Canvasbacks. Journal of Wildlife Management 65: 385-397.

Arnold, T. W. 2011. Onset of incubation and patterns of hatching in the American Coot. Condor 113: 107118.

Blums, P., A. Mednis and J. D. Nichols. 1994. Retention of web tags and plasticine-filled leg bands applied to day-old ducklings. Journal of Wildlife Management 58: 76-81.

Eadie, J. and B. E. Lyon. 1998. Cooperation, conflict, and creching behavior in goldeneye ducks. American Naturalist 151: 397-408.

Eichhorst, B. E. 1986. The food habits of juvenile American Coots (Fulica americana) on Rush Lake, Winnebago County, Wisconsin. Unpublished M.Sc. Thesis, University of Wisconsin, Oshkosh, Wisconsin.

Evans, C. D. 1951. A method of color marking young waterfowl. Journal of Wildlife Management 15: 101103.

Foley, D. D. 1956. Use of colored markers on ducklings. New York Fish and Game Journal 3: 240-247.

Gullion, G. W. 1951. A marker for waterfowl. Journal of Wildlife Management 15: 222-223.

Kehoe, P. F. and K. Mawhinney. 1999. Evaluation of various methods used to color mark ducklings. Canadian Field-Naturalist 113: 675-677.

Korschgen, C. E., K. P. Kenow, W. L. Green, D. H. Johnson, M. D. Samuel and L. Sileo. 1996. Survival of radiomarked Canvasback ducklings in northwestern Minnesota. Journal of Wildlife Management 60: 120-132.

Lyon, B. E. 1993. Brood parasitism as a flexible female reproductive tactic in American Coots. Animal Behaviour 46: 911-928.

Lyon, B. E., J. M. Eadie and L. D. Hamilton. 1994. Parental choice selects for ornamental plumage in American Coot chicks. Nature 371: 240-243.

Mauser, D. M. and R. L. Jarvis. 1991. Attaching radio transmitters to 1-day-old Mallard ducklings. Journal of Wildlife Management 55: 488-491.

Mehl, K. R. and R. T. Alisauskas. 2007. King Eider (Somateria spectabilis) brood ecology: correlates of duckling survival. Auk 124: 606-618. 
Pelayo, J. T. 2001. Correlates and consequences of egg size variation in wild Ruddy Ducks (Oxyura jamaicensis). Unpublished M.Sc. Thesis, University of Saskatchewan, Saskatoon, Saskatchewan.

Pelayo, J. T. and R. G. Clark. 2003. Consequences of egg size for offspring survival: A cross-fostering experiment in Ruddy Ducks (Oxyura jamaicensis). Auk 120: 384-393.

Reed, W. R., M. E. Clark and C. M. Vleck. 2009. Maternal effects increase within-family variation in offspring survival. American Naturalist 174: 685-695.

Sharpe, F., M. Bolton, R. Sheldon and N. Ratcliffe. 2009. Effects of color banding, radio tagging, and repeated handling on the condition and survival of Lapwing chicks and consequences for estimates of breeding productivity. Journal of Field Ornithology 80: 101-110.

Shizuka, D. and B. E. Lyon. 2010. Coots use hatch order to learn to recognize and reject conspecific brood parasitic chicks. Nature 463: 223-226.

Sugden, L. G. and H. J. Poston. 1968. A nasal marker for ducks. Journal of Wildlife Management 32: 984-986.

Traylor, J. J. and R. T. Alisauskas. 2006. Effects of intrinsic and extrinsic factors on survival of White-winged Scoter (Melanitta fusca deglandi) ducklings. Auk 123: 67-81.

White, G. C. and K. P. Burnham. 1999. Program MARK: Survival estimation from populations of marked animals. Bird Study 46 (Suppl.): 120-138. 